\title{
As novas utopias piratas: Uma análise de wikis e projetos colaborativos através da Zona Autônoma Temporária de Hakim Bey
}

\author{
Marcelo Benevides Lopes ${ }^{1}$ \\ Universidade Federal de Pernambuco \\ benevidesmarcelo@yahoo.com.br
}

\begin{abstract}
Resumo: A proposta do presente artigo é aprofundar e atualizar os conceitos desenvolvidos pelo escritor norte-americano Hakim Bey no livro TAZ: Zona Autônoma Temporária, através das metáforas do rizoma e da máquina de guerra, descritas por Gilles Deleuze e Félix Guattari, e de outros desdobramentos que se tornam necessários, tendo como suporte autores como Michel Foucault, Zygmunt Bauman e Howard Rheingold. Assim, sugerimos situar a formação da TAZ no âmbito da cibercultura, mais precisamente em sistemas colaborativos que utilizam a plataforma wiki, também propondo uma contextualização da cartografia da rede e dos dispositivos de vigilância em tais projetos.
\end{abstract}

Palavras-Chave: Zona Autônoma Temporária 1. Cibercultura 2. Colaboração 3.

\begin{abstract}
This paper aims at deepening and updating the concepts developped by North-American writer Hakim Bey in TAZ: Temporary Autonomous Zone, through using Gilles Deleuze's and Félix Guattari's Rhizome and War Machine metaphors, together with other developments, and also based on the work by authors such as Michel Foucault, Zygmunt Bauman and Howard Rheingold. Thus, we suggest locating the TAZ building process under the cyberculture sphere, more specifically in the collaborative systems which use the wiki platform, also proposing to contextualize the network cartography and the surveillance gadgets inside these projects.
\end{abstract}

Keywords: Temporary Autonomous Zone 1. Cyberculture 2. Collaboration 3 .

${ }^{1}$ Jornalista, mestrando do Programa de Pós-Graduação em Comunicação da Universidade Federal de Pernambuco. 
Résumé: L'article présent propose d'approfondir et de moderniser les concepts développés dans le livre "Zone autonome temporaire" (TAZ) écrit par Hakim Bey en faisant usage des métaphores du rhizome et de la machine de guerre, décrites par Gilles Deleuze et Félix Guattari. Cet article se base sur des auteurs comme Michel Foucault, Zygmunt Bauman et Howard Rheingold. Ainsi, nous placons ce phénomène des TAZ dans le contexte de la ciberculture, notamment dans des systèmes participatives qui utilisent la plateforme wiki et ceci en proposant une cartographie du réseau et des ispositifs de surveillance.

Mot-clés : Zone Autonome Temporaire 1. Ciberculture 2. Collaboration 3.

Resumen: El propósito del presente artículo es atualizar los conceptos desenvolvidos por el escritor norte-americano Hakim Bey en el libro TAZ: Zona Autónoma Temporaria, por el medio de las metáforas del rizoma y de las máquina de guerra describidas por Gilles Deleuze e Félix Guatarri, y de otros desarollamentos que se véem necesarios, teniendo como apoyo autores como Michel Foucault, Zygmund Bauman y Howard Rheingold. De esa manera, sugerimos ubicar la formación de la TAZ en el ámbito de la cibercultura, más precisamente en sistemas colaborativos que utilizam la plataforma wiki, también proponendo una contextualización de la cartografia de la rede y de los dispositivos de vigilancia en dichos proyectos.

Palabras clave: Zona Autónoma Temporaria 1. Cibercultura 2. Colaboración 3.

\section{Introdução: ilhas na rede}

No final da década de 80, o ensaísta Hakim $\mathrm{Bey}^{2}$ (2004) reuniu uma série de conceitos inspirados nas mais variadas vertentes de estudos para propor o que definiu como Zonas Autônomas Temporárias (aqui chamadas de TAZ, sigla obtida da expressão original em inglês 3 ). Partindo do que denomina de "utopias piratas", para se referir às redes de informação montadas por corsários do século XVIII, Bey cita as ilhas em que estas mini-sociedades viviam, "conscientemente fora-da-lei" (BEY, 2004, p. 11), que funcionavam como abrigo e posto de troca de artigos adquiridos durante as pilhagens. Ampliando o conceito da TAZ, o autor defende a abstração da expressão e seu poder de auto-explicação a partir do próprio nome. Zonas livres de enclaves hierárquicos e de formação espontânea e estratégica seriam as estruturas

\footnotetext{
${ }^{2}$ Pseudônimo do filósofo anarquista Peter Lamborn Wilson.

3 Temporary Autonomous Zone.
} 
adequadas para as recentes maneiras de insurreição - fazendo contraponto à "revolução", a insurreição contaria com a vantagem de maximizar seus momentos de ápice, a verdadeira razão de existir da TAZ. Dessa forma, a ideologia poderia ser utilizada nos campos variados da arte (movimentos, redes de produção e circulação) e da cultura em geral, também absorvendo um potencial de sobrevivência frente ao "Império do Espetáculo e da Simulação". Seria uma "tática de desaparecimento" (BEY, 2004, p. 62), já que a TAZ apresenta a característica rizomática de territorializar-se e reterritorializar-se (DELEUZE; GUATTARI, 1995) continuamente:

A formação de redes de conexões, como uma alternativa para a política, é praticada em muitos níveis da sociedade, e organizações não-hierárquicas têm conseguido bastante popularidade mesmo fora do movimento anarquista, simplesmente porque essas redes funcionam. (BEY, 2004, p. 65).

O rizoma é, assim, a metáfora que dá corpo ao projeto da Zona Autônoma Temporária. Sua estrutura descentralizada segue princípios como conexão, heterogeneidade, multiplicidade e ruptura. Assim como a TAZ, são formados, ampliados e interconectados continuamente, sem ordem fixa, lutando contra o que Deleuze e Guattari (1995) chamam de "fechamento do mapa”. A dupla de autores define, então, a "máquina de guerra", distinta das instituições militares, exterior ao Aparelho do Estado e que teria o nômade como agente. Este, por sua vez, não se fixaria, necessariamente, em pontos específicos ou previamente delineados por órgãos do poder responsáveis pelo "estriamento do espaço", estando sempre no intermezzo, na sua peculiar delimitação cartográfica. A semelhança da máquina de guerra com a TAZ também se encontra em sua capacidade de mutação, caso seja vencida pelo Estado: “é no mesmo movimento que a máquina de guerra já está ultrapassada, condenada, apropriada, que ela toma novas formas, se metamorfoseia, afirmando sua irredutibilidade, sua exterioridade" (DELEUZE; GUATTARI, 1997, p. 18). Ainda levando em consideração o pensamento deleuziano, Bauman (2001, p. 228) define as cloakroom communities ${ }^{4}$, manifestações explosivas características de uma fase da modernidade em que a territorialidade não é mais necessária para que ajuntamentos livres possam existir, surgindo e desaparecendo, "com duração curta, mas cheia de som e fúria”.

\footnotetext{
4 Traduzindo-se literalmente, "comunidades de guarda-casacos”, em alusão aos locais onde, em museus e teatros, deixam-se capas e casacos, que são retirados à saída.
} 
Discorrendo a respeito de ambientes onde as TAZ têm potencial de desenvolvimento, a internet seria uma das ferramentas fundamentais para a formação dessas zonas de controle diferenciado. Bey situa uma contra-net (definida como $w e b$ ) dentro da própria internet, usada de forma clandestina, que inclui desde a pirataria de dados até a formação de sistemas alternativos de informação, o que nos faz lembrar da diferenciação entre tática e estratégia propagada por Certeau (1996), para quem as táticas não possuem um território próprio, nem uma fronteira; não são um ataque frontal contra um poder externo, mas infiltrações temporárias a partir do interior do território inimigo. Em entrevista realizada em 2002 para a revista High Times, Hakim Bey afirmou que o objetivo não é considerar a internet em si como uma TAZ, e sim como uma ferramenta para a formação das mesmas, já que a criação das Zonas Autônomas Temporárias está diretamente vinculada ao mundo físico. Aqui, a proposta é reiterar a importância da $w e b$ como facilitadora de tais processos, levando em consideração, como lembra Lemos (2002), que o ciberespaço não pode ser analisado à parte da realidade sociocultural de cada pólo produtor de informação. Por outro lado, faz-se necessário observar de que maneira estas organizações atuam de forma a evitar o risco anunciado por Rheingold (1996, p. 315) de que tais comunidades virtuais contemporâneas se tornem "enclaves informáticos, torres de marfim intelectuais".

Considerando que os textos que compõem o livro de Hakim Bey foram escritos na década de 80, quando a Rede apresentava-se de maneira ainda embrionária, sob a forma de sistemas de BBS e e-mail, cabe-nos analisar o conceito da TAZ à luz dos projetos colaborativos na internet, organizações que hoje mais se aproximam das definições do autor em relação às comunidades virtuais. Aqui, diante de tais possibilidades, escolhemos o universo dos wikis, conjuntos hipertextuais cujas estruturas permitem a intervenção de quaisquer usuários, devido a sua fluidez, forma de funcionamento não-hierárquico e capacidade de adaptação a diversas ideologias empresariais, educacionais, ativistas, etc. A abordagem parte da formação e dinâmicas intrínsecas a esses lugares e aos processos de territorialização, desterritorialização e reterritorialização na contemporaneidade, lançando um olhar sobre essa nova cartografia. Assim, naturalmente, tendo os wikis como foco, pode-se traçar um breve panorama das relações entre TAZ, web e colaboração. Observando os 
princípios de organização de tais ambientes, vemos como fator necessário, também, investigar de que forma a disciplina é apresentada nestes projetos.

\section{A cartografia da rede: espaços, TAZ e experiências na web}

Para Deleuze e Guattari (1997, p. 180), os espaços liso e estriado, onde respectivamente se desenvolvem a máquina de guerra e o aparelho do Estado, entrecruzam-se e dissolvem-se continuamente: “o espaço liso não pára de ser traduzido, transvertido num espaço estriado; o espaço estriado é constantemente revertido, devolvido a um espaço liso”. Em outras palavras, o processo de estriagem do espaço (o mar, para os autores, seria o espaço liso por excelência) e seu posterior alisamento seriam dados através dos modernos aparelhos de Estado de organização de capital. O que interessa aos autores é justamente essa dinâmica de recriação de espaços lisos, considerando a proposta nômade de desenhar seu próprio mapa à medida que seu deslocamento é efetuado (nunca no ponto, sempre no intermezzo, sempre em movimento), traçando linhas de fuga contra a verticalização proposta por modelos dominantes:

O que nos interessa são as passagens e as combinações, nas operações de estriagem, de alisamento. Como o espaço é constantemente estriado sob a coação de forças que nele se exercem; mas também como ele desenvolve outras forças e secreta novos espaços lisos através da estriagem. Mesmo a cidade mais estriada secreta espaços lisos: habitar a cidade como nômade, ou troglodita. Às vezes bastam movimentos, de velocidade ou de lentidão, para recriar um espaço liso. Evidentemente, os espaços lisos por si só não são libertadores. Mas é neles que a luta muda, se desloca, e que a vida reconstitui seus desafios, afronta novos obstáculos, inventa novos andamentos, modifica os adversários. Jamais acreditar que um espaço liso basta para nos salvar. (DELEUZE; GUATTARI, p. 214)

Por outro lado, levando em consideração a extraterritorialização do poder na contemporaneidade, Bauman (2001, p. 137) defende que a mudança entre relações de capital e trabalho nos faz passar de um universo do hardware para a época do software - a conquista territorial e a "quase instantaneidade do tempo" anunciam a desvalorização do espaço, ou, mais precisamente, a formação de "não-lugares" (AUGÉ, 2006), vazios de idiossincrasias e subjetividades, e de "espaços vazios", onde a negociação de diferenças nunca surge. Como lembra Tarde (2003, p. 70), no entanto, "existir é diferir": as relações de alteridade e a presença de aparatos de 
controle nas redes eletrônicas de informação não se extinguem, mas devem "continuar a desfazer-se e petrificar-se simultaneamente, devem prosseguir em seu curso atual, onde a rigidez histérica cada vez mais mascara um vazio, um abismo de poder" (BEY, 2004, p. 72).

Apropriamo-nos aqui, dessa forma, do conceito de "heterotopia" (FOUCAULT, 1967), que seriam "espaços dessacralizados", inerentes a várias culturas, privilegiados, proibidos ou de crise, onde se abrigam indivíduos cujos comportamentos são desviantes em relação à média necessária. Para Foucault, “cada heterotopia tem uma função determinada e precisa na sua sociedade, e essa mesma heterotopia pode, de acordo sincrônico com a cultura em que se insere, assumir uma outra função qualquer”. É importante lembrar que os processos de remediação (BOLTER; GRUSIN, 2002) sofridos pelas práticas colaborativas estimuladas nos ambientes virtuais não podem ser analisados separadamente de seus arranjos sociais. Se por um lado, as heterotopias acolhem os desviantes, no âmbito da cibercultura entendida como manifestação da sociedade contemporânea - são justamente o excesso, a despesa, o desvio que movem tais círculos de produção e circulação de informação e produtos culturais. Afinal, como afirma Lemos (2004, p. 185), "a cibercultura foi criada por uma espécie de resistência ao poder da tecnocracia, tratando-se mesmo de uma diferenciação em relação ao uso da tecnologia”. Ou, como defende Bey (2004, p. 72), "sem a web, a completa realização do complexo da TAZ não será possível. Mas a web não é um fim em si mesma. É uma arma”. Caetano (2006, p. 86), atualizando os conceitos deleuzianos, reforça que "hoje, os guerreiros resistentes da internet atuam num terreno semelhante. Os espaços desterritorializados do ciberespaço são zonas nômades-rizomáticas-lisas”.

As práticas destacadas por Hakim Bey na formação da TAZ, como guerrilha, desaparecimento e recusa à institucionalidade, reforçam o movimento do nômade em favor do turbilhonamento do(s) espaço(s). Como lembra Caetano (2006, p. 90), uma das contribuições mais importantes da internet é "possibilitar a existência de algumas estruturas não-hierarquizadas de produção e divulgação do conhecimento". Nesse aspecto, os projetos de construção colaborativa de conteúdo são fundamentais para o entendimento da formação de Zonas Autônomas Temporárias a partir de iniciativas 
tomadas no ciberespaço. É o caso de coletivos artísticos como o Re:combo ${ }^{5}$ que, unindo músicos, artistas plásticos, engenheiros de software, DJs e acadêmicos, trabalha em projetos de arte digital e música de forma descentralizada, sob a ideologia do copyleft, contraponto ao monopólio da propriedade intelectual traçada pelas leis de copyright. Com um viés mais radical, também se destaca o Critical Art Ensemble $^{6}$ (CAE), que explora as relações entre arte, tecnologia, política radical e teoria crítica. Para o CAE, a liquefação da sociedade moderna, como lembra Bauman (2001), faz com o que o poder também se dilua. A solução, então, seria a formação de espécies de bunkers no ciberespaço onde a força nômade resista contra "o arcaico modelo de distribuição de poder e estratégias predatórias que têm sido inventadas pela elite do capitalismo tardio pelos mesmos fins" (CRITICAL ART ENSEMBLE, 1994, p. 15, T. do A.), promovendo o que o coletivo intitula de "desobediência civil eletrônica" (CRITICAL ART ENSEMBLE, 2001).

Assim, após expor este breve panorama a respeito da formação de comunidades virtuais e de projetos de construção colaborativa na $w e b$, chegamos aos wikis, escolhidos aqui como ferramentas facilitadoras da criação da TAZ devido à sua estrutura aberta e possibilidade de constantes mutações.

\subsection{A TAZ e os wikis}

A plataforma Wiki, idealizada pelo programador Ward Cunningham em 1995, é uma das possibilidades colaborativas em destaque na web. Basicamente, um wiki7 é definido como uma série de documentos hipertextuais que podem ser criados e modificados por qualquer usuário, sem o prévio domínio aprofundado de programas específicos, apenas utilizando algum navegador comum (como Internet Explorer, Mozilla Firefox, Netscape e Opera) ou qualquer outro software capaz de ler linguagem HTML e imagens. Seu maior representante é a Wikipédia ${ }^{8}$, enciclopédia online criada em 2001, sem fins lucrativos e operada pela Wikimedia Foundation. $\mathrm{O}$ projeto possui aproximadamente 7,5 milhões de artigos $^{9}$, divididos nas versões idiomáticas do site. O emprego dos wikis, no entanto, tem ocorrido em diversas

\footnotetext{
5 http://www.recombo.art.br

${ }^{6} \mathrm{http}: / /$ www.critical-art.net

7 Expressão havaiana que significa "rápido".

8 http://www.wikipedia.org

9 Em acesso realizado em 8 de agosto de 2007.
} 
áreas, com os mais variados propósitos. O que faz com que a ferramenta se torne facilitadora da TAZ é a sua utilização como instrumento alternativo a veículos e meios de produção convencionais. A própria Wikipédia, autointitulada "a enciclopédia livre", surge como opção em relação a enciclopédias tradicionais, como Britannica e Encarta. Em outros casos, os wikis são usados como forma de difundir obras que se encontram livres para uso (em outras palavras, em “domínio público”), como acontece com a International Music Score Library Project ${ }^{10}$, que disponibiliza partituras musicais gratuitamente na $w e b$. A plataforma ainda é utilizada para reunir grupos de interesse, como o Memory Alpha ${ }^{11}$, voltado a aficionados pelo filme Star Trek ou, simplesmente, para desconstruir, ironicamente, idéias difundidas (ou não) pelos mass media, como é o caso da Desciclopédia. Neste projeto, que parodia a Wikipédia, tem-se, por exemplo, na abertura do verbete "Deus"12:

Deus é o pseudônimo de Eric Clapton, Senhor dos Céus e Deus Supremo da Mitologia Grega. Filho mais novo de Cronos, Rei dos Titãs (vilões da nova trama dos Cavaleiros do Ridículo, Episódio Gay), dos Paralamas e até mesmo do Yahoo ("Volta pra casa, eu preciso te ver") e Réia, nascido no Monte Ida, Ilha de Creta. Conhecido pelo nome Romano de Júpiter, tinha como irmãos Poseidon, Hades, Deméter, Héstia, Heve e Hera de quem era também marido, e pai de diversos deuses, como Atena, Ártemis e Apolo, e semi-deuses, como Hércules. É uma mercadoria vendida e nunca entregue por ambas as companhias. Curiosamente, todas as companhias afirmam ter o monopólio dessa mercadoria.

Lembrando a explicação de Hakim Bey (2004, p. 17), a formação da TAZ não confronta as organizações de poder diretamente, não levando necessariamente à violência ou ao martírio, e sim a "uma operação de guerrilha que libera uma área (de terra, de tempo, de imaginação) e se dissolve para se refazer em outro lugar e outro momento, antes que o Estado possa esmagá-la”. Caso esse esmagamento aconteça de fato, como prevêem Deleuze e Guattari (1997), a máquina de guerra então é enquadrada pelos aparatos de poder do Estado, mas sua estrutura rizomática fluida aqui presente nos wikis - faz com que, seguindo o princípio da ruptura, "possa ser rompida, quebrada em qualquer lugar, e também retoma segundo uma ou outra de suas linhas e seguindo outras linhas" (DELEUZE; GUATTARI, 1995, p. 17), compreendendo "linhas de desterritorialização" pelas quais se transmuta sem parar.

\footnotetext{
${ }^{10} \mathrm{http} / /$ imslp.org/wiki/P\%C3\%A1gina_inicial

${ }^{11} \mathrm{http}: / /$ memory-alpha.org/en/wiki/Portal:Main

${ }^{12} \mathrm{http}: / /$ desciclo.pedia.ws/wiki/Deus
} 
Como reitera Morais (2004), "a idéia é a de que o espaço virtual teria se tornado tão ou mais importante que o físico na disputa do poder”. É o que defende Rheingold (2002), ao analisar as práticas colaborativas e atividades realizadas com o uso de tecnologias móveis, como aparelhos de telefonia celular.

Para Bowman e Willis (2003), uma das principais características dos projetos que utilizam wikis é a sua capacidade de auto-regulação. Afinal de contas, os sites que contam com tal tecnologia disponibilizam um histórico de alterações que permite a manutenção frente a possíveis atos que não correspondam às políticas de convivência de cada comunidade - é uma forma de disciplinar a "multiplicidade de individualidades" (TARDE, 1992) que formam tais agrupamentos, por mais que o fluxo livre de informações defendido por Hakim Bey não possa ser detido, mas deva ser relativizado. A fluidez da estrutura dos wikis e o seu uso para a construção de meios de informação alternativos ao modo de produção presentes no mainstream (o chamado grassroots, termo adotado pelos entusiastas do colaborativismo e da mídia tática em geral) nos remetem, de fato, à idéia da formação de TAZ em ritmo constante de mutação, ausência de hierarquia e a potencialização do fator descentralizador que caracteriza a liberação do pólo emissor que define a comunicação na internet. A capacidade de auto-regulação destes organismos, no entanto, é o que nos chama a atenção aqui. Como Bey sugere, a expansão das TAZ depende de uma tática de desaparecimento; em outras palavras, o autor defende que a própria noção de poder perdeu seu sentido e se tornou pura simulação. Resta, então, a prática de gestos simbólicos contra instituições dominantes:

A TAZ aconteceu, está acontecendo e vai acontecer com ou sem o computador. Mas para que a TAZ realize plenamente seu potencial, ela deve tornar-se menos um caso de combustão espontânea e mais uma situação de "ilhas na net". A net, ou melhor, a contra-net assume a promessa de ser um aspecto integral da TAZ, uma adição que irá multiplicar o seu potencial, um salto "quantum", um salto enorme em termos de complexidade e significância. (BEY, 2004, p. 41)

A formação de projetos que utilizam wikis, então, traz a lembrança das "utopias piratas" citadas anteriormente. O surgimento dessas "ilhas na rede", porém, não ocorre mais necessariamente de forma clandestina, tampouco ilegal. A velocidade com que seus territórios informacionais se movimentam, entretanto, faz com que verifiquemos os operadores de vigilância que são utilizados nestes sistemas. 
Afinal, como lembra Bey, mesmo os bandos (alternativa às formações familiares hierarquizadas) possuem certas regras de organização. É o que analisaremos a seguir, observando o funcionamento de tais dispositivos no ciberespaço e, mais especificamente, em ambientes colaborativos.

\section{Vigilância e interesses comuns}

A maneira como a disciplina é produzida de acordo com a organização da sociedade é um dos eixos do trabalho de Michel Foucault (1987), que vê o poder disciplinar como uma força que agrega indivíduos e que se apresenta de forma inverificável. De maneira a categorizar os membros de um grupo e estabelecer padrões normalizadores que terminam por redirecionar os representantes da ordem "desviante" a instituições como a escola (por ser um aparelho de avaliação constante), a prisão e o hospício, tal poder acaba por se relacionar diretamente com o saber, neste processo de formação pessoal:

O indivíduo é, sem dúvida, o átomo fictício de uma representação "ideológica" da sociedade; mas é também uma realidade fabricada por essa tecnologia específica de poder que se chama a "disciplina". Temos que deixar de descrever sempre os efeitos de poder em termos negativos: ele "exclui", "reprime", "recalca", "censura", "abstrai", "mascara", "esconde". Na verdade o poder produz; ele produz realidade; produz campos de objetos e rituais de verdade. $\mathrm{O}$ indivíduo e o conhecimento que dele se pode ter se originam nessa produção. (FOUCAULT, 1987, p. 161)

Deleuze (2005), retomando a proposta de Foucault, lembra que o poder nunca é global nem localizável, porque é difuso. Dessa forma, o desenvolvimento dos mecanismos disciplinares está diretamente ligado ao aprimoramento de novas tecnologias porque, como lembra o autor, estes próprios mecanismos são, eles mesmos, aparatos tecnológicos: sugere, então, a passagem da disciplina ao controle (DELEUZE, 1992), que ocorreria no século XX, e o surgimento de novas formas de dominação, já que o modelo indicado anteriormente por Foucault se caracterizaria pela brevidade: "o controle é de curto prazo e de rotação rápida, mas também contínuo e ilimitado". Para Ottaviani (2003), os sistemas disciplinares entram em crise justamente por sua segmentação rígida (o "universo do hardware”, de Bauman) e por mudanças nos tipos de organização empresarial, seguindo a ordem desterritorializante própria da contemporaneidade. $\mathrm{O}$ autor nos remete à heterotopia, 
já definida aqui, para fixar as populações, evitando os nomadismos e promovendo o enquadramento.

A idéia de Deleuze (1992) a respeito da sociedade do controle e sua ligação com o surgimento das redes informáticas restaura a possibilidade de a máquina de guerra ser tomada pelos aparelhos do Estado, sendo remontada no ciberespaço: "as sociedades de controle operam por máquinas de uma terceira espécie, máquinas de informática e computadores, cujo perigo passivo é a interferência, e o ativo a pirataria e a introdução de vírus”. Assim, retomamos Lemos (2004, p. 183) para reforçar que o que move a cibercultura é justamente o desvio e a apropriação do excesso: "a sociedade contemporânea institui-se como uma disseminação virótica de dados binários sob diversas formas: samplings musicais, vírus, pirataria, colagens digitais, etc.”. Além disso, lembramos também que as próprias ferramentas da internet vêm sendo desenvolvidas, desde a formação da Rede, por sujeitos supostamente tidos como "desviantes" pelo resto da sociedade: hackers, cyberpunks, etc. Dessa forma, a apropriação da máquina de guerra (as tecnologias libertadoras citadas por Hakim Bey para a formação das TAZ) pelas instituições de poder seria um processo inerente à estrutura descentralizada da $w e b$. Paralelamente, por sua vez, ocorreria a formação de novos agrupamentos e fluidificações que propagariam a proposta libertária dos projetos colaborativos, como previram Deleuze e Guattari na identificação do rizoma.

As atividades cooperativas na internet fazem com que resgatemos a hipótese apocalíptica de "interesse comum" descrita por Garrett Hardin (1968, T. do A.). Adotando a teoria malthusiana de crescimento populacional, o autor ilustra as questões de moralidade presentes no funcionamento de uma comunidade: "cada homem está trancado num sistema que o compele a aumentar sua produção sem limites - num mundo que tem limites”. Partindo deste pensamento, Rheingold (2002) sugere os esquemas de reputação e cooperação nos processos de produção coletiva, chegando ao que chama de Dilemas de Ação Coletiva, que seria a tentativa de equilíbrio contínuo entre o interesse dos membros dos projetos e os interesses públicos. Dessa forma, para contrabalançar tais interesses e minimizar os efeitos de embates travados em tais ambientes, cria-se a necessidade de estabelecimento de sistemas de auto-regulação, vigilância e controle. O autor resgata, então, a idéia de Foucault (1987) do Panoptismo (inspirada na composição arquitetônica de cunho 
coercitivo e disciplinatório proposta por Jeremy Bentham no século XVIII) para questionar os riscos que permeiam a atividade colaborativa: ameaças à liberdade individual, à qualidade de vida e à dignidade humana. Lembra, ainda, que o poder e o contra-poder podem, algumas vezes, ser combinados para a criação de bens de interesse comum no ciberespaço: "toda ordem social, não apenas as repressivas, requerem métodos de controle social mútuo" (RHEINGOLD, 2002, p. 190, T. do A.). É justamente a ideologia dos membros de comunidades wiki, como se pode observar num trecho do verbete "Wiki"13 da Wikipédia:

A idéia por trás de controlar usuários é diretamente relacionada ao tamanho do universo gerado pelo wiki. Quanto mais pessoas estiverem usando o wiki, menor deveria ser a necessidade de níveis de controle, pois o controle é fornecido pela própria sociedade. Mas o controle sempre se faz necessário, em pelo menos dois níveis: gerenciamento e utilização.

Desta forma um wiki muito pequeno costuma ter a necessidade de adicionar um controle que impede autores anônimos para evitar vandalismo. Por outro lado, a maioria dos wikis públicos, que costumam ser grandes, dispensa qualquer tipo de registro.

Dessa forma, Bauman (2001, p. 101) anuncia o fim do Panoptismo e do engajamento mútuo entre supervisores e supervisados, capital e trabalho, líderes e seguidores, exércitos em guerra. Seria a chegada do que o autor chama de "Sinoptismo":

As mesas foram viradas e agora são muitos que observam poucos (...). A obediência aos padrões (uma maleável e estranhamente ajustável obediência a padrões eminentemente flexíveis, acrescento) tende a ser alcançada hoje em dia pela tentação e pela sedução e não mais pela coerção - e aparece sob o disfarce do livre arbítrio, em vez de revelar-se como força externa.

A construção colaborativa de conteúdo funcionaria, frente a essa ilusão de liberdade prevista por Bauman e Rheingold, com a formação de projetos colaborativos na internet como "micro-células de resistência" (CRITICAL ART ENSEMBLE, 1994), representadas aqui pelos wikis e metaforizadas pela TAZ de Hakim Bey. As possibilidades levantadas por tais ferramentas, como vimos, devem ser analisadas de acordo com as finalidades com que as mesmas são utilizadas: comunitaristas, ativistas, governamentais e/ou institucionais. Afinal, além dos

${ }_{13}$ http://pt.wikipedia.org/wiki/Wiki 
conflitos ideológicos e culturais entre os indivíduos envolvidos e os grupos a que estão ligados, naturalmente também surgem questionamentos - e providências - a respeito da vigilância em tais ambientes.

\section{Considerações finais}

Para Bauman (2001), a "modernidade sólida" era a época do engajamento mútuo; atualmente, com o que o autor chama de "modernidade líquida", entramos na era do desengajamento, quando se destacam os mais escapadiços, livres para se mover de modo imperceptível. Dentro desse processo, Hakim Bey nos lembra que o mapa está se fechando, mas a Zona Autônoma Temporária está aberta - é a busca pelo alisamento dos espaços prescrita por Deleuze e Guattari (1997) - e, constantemente, aprimorando suas táticas de desaparecimento. Assim, mais uma vez, afirmamos que a TAZ, uma retomada contemporânea da máquina de guerra, não enfrenta diretamente o poder, pois o mesmo não é mais localizável, também se distribuindo de acordo com extraterritorialidade que caracteriza a internet. Bey (2004, p. 29) romantiza o ativismo - aqui entendido como expressões sob a forma de movimentos artístico-culturais, políticos e também como a construção de projetos colaborativos - como "interzonas ${ }^{14}$, oásis fortificados escondidos nas rotas das caravanas secretas, trechos de selvas e sertões 'liberados', áreas proibidas, mercados negros e bazares underground".

Tentamos nos aprofundar no conceito de TAZ desenvolvido por Hakim Bey através do funcionamento dos sistemas colaborativos de produção de conteúdo, tendo como foco, mais especificamente, os wikis. Pelo modo como esta ferramenta é operada e por sua estrutura constantemente mutável, sujeita a alterações e intervenções por quaisquer usuários (no caso de sites não-corporativos e realmente abertos), percebemos que a plataforma pode ser utilizada para a formação das Zonas Autônomas Temporárias. Entretanto, como alerta Rheingold (2002, p. 197, T. do A.), “a democratização do poder de publicação permitido por redes de informação 'muitos-a-muitos' poderia significar a morte do social no ciberespaço através do lixo informacional”. Quando se trata de atividades coletivas, porém, como defendemos antes, o excesso pode ser uma virtude em tais espaços. O cuidado que se deve ser

\footnotetext{
${ }_{14}$ Uma alusão a uma espécie zona liberada presente no romance $A l m o c ̧ o ~ N u$, do escritor beat
} norte-americano William S. Burroughs. 
tomado, portanto, é de levar em consideração as possibilidades de confrontamento entre seus participantes (a própria TAZ não é marcada pela homogeneidade de seus integrantes) e os processos de normatização ocorrentes em tais ambientes, caracterizando os sistemas de vigilância nos projetos colaborativos que trabalham sob a plataforma wiki.

\section{Referências Bibliográficas}

AUGÉ, Marc. Sobremodernidade: do mundo tecnológico de hoje ao desafio essencial de amanhã. In: MORAES, D.(org.). Sociedade Midiatizada. Rio de Janeiro: Mauad, 2006.

BAUMAN, Zygmunt. Modernidade líquida. Rio de Janeiro: Jorge Zahar Ed., 2001.

BEY, Hakim. TAZ: zona autônoma temporária. 2. ed. São Paulo: Conrad, 2004.

BOLTER, Jay David; GRUSIN, Richard. Remediation: understanding new media. Cambridge, Massachusetts: MIT Press, 2002.

BOWMAN, Shayne; WILLIS, Chris. We Media: How audiences are shaping the future of news and information. The Media Center at The American Press Institute, 2003. Disponível em: <http://www.hypergene.net/wemedia/download/we_media.pdf>. Acesso em: o9 de agosto de 2007.

BURROUGHS, William S. Almoço nu. Rio de Janeiro: Ediouro, 2005.

CAETANO, Miguel Afonso. Tecnologias de resistência: transgressão e solidariedade nos media tácticos. 269 f. Dissertação (Mestrado em Comunicação, Cultura e Tecnologias da Informação). Instituto Superior de Ciências do Trabalho e da Empresa, Lisboa, Portugal, 2006.

CERTEAU, Michel de. A invenção do cotidiano: artes de fazer. 2. ed. Petrópolis: Vozes, 1996

CRITICAL ART ENSEMBLE. The electronic disturbance. Nova York: Autonomedia, 1994. Disponível online em <http://www.criticalart.net/books/ted/index.html>. Acesso em 9 de agosto de 2007.

CRITICAL ART ENSEMBLE. Digital resistance: explorations in tactical media Nova York: Autonomedia, 2001. Disponível online em <http://www.criticalart.net/books/digital/index.html>. Acesso em 9 de agosto de 2007.

DELEUZE, Gilles; GUATTARI, Félix. Mil platôs: capitalismo e esquizofrenia. v. 1. São Paulo: ed. 34, 1995.

v. 5. São Paulo: ed. 34, 1997. Mil platôs: capitalismo e esquizofrenia. 
DELEUZE, Gilles. Foucault. São Paulo: Brasiliense, 2005.

. Post-scriptum sobre as sociedades do controle. In:

. Conversações: 1972-1990. Rio de Janeiro: Editora 34, 1992.

p.219-226. Disponível online em

<http://netart.incubadora.fapesp.br/portal/midias/controle.pdf > . Acesso em 9 de agosto de 2007.

ENTREVISTA com Hakim Bey na High Times Magazine. Disponível online em $<$ http://www.rizoma.net/interna.php?id=149\&secao=intervencao $>$. Acesso em 8 de agosto de 2007.

FOUCAULT, Michel. Vigiar e punir: nascimento da prisão. Petrópolis: Vozes, 1987.

. De outros espaços. Conferência proferida no Cercle d'Études Architecturales, em 14 de Março de 1967. Disponível online em $<$ http://www.rizoma.net/interna.php?id=169\&secao=anarquitextura $>$. Acesso em 17 de julho de 2007.

HARDIN, Garrett. The Tragedy of the Commons. Science. v. 162, 1968. p. 1243-1248. Disponível online em <http://dieoff.org/page95.htm>. Acesso em 9 de agosto de 2007.

LEMOS, André. Cibercultura: tecnologia e vida social na cultura contemporânea. Porto Alegre: Sulina, 2002.

. Apropriação, desvio e despesa na cibercultura. In: MARTINS, Francisco Menezes; SILVA, Juremir Machado da (orgs). Genealogia do virtual: comunicação, cultura e tecnologias do imaginário. Porto Alegre: Sulina, 2004.

MORAIS, Rodrigo de Oliveira. Zona autônoma temporária: web e máquinas de guerra. Trabalho apresentado ao Núcleo de Pesquisa Tecnologias da Informação e da Comunicação, durante o IV Encontro dos Núcleos de Pesquisa da Intercom, em 2004.

OTTAVIANI, Didier. Foucault - Deleuze: de la discipline au contrôle. In: SILVA, Emmanuel da (org.). Lectures de Michel Foucault: Foucault et la philosophie. Paris: ENS Éditions, 2003.

RHEINGOLD, Howard. A comunidade virtual. Lisboa: Gradiva, 1996. Perseus Publishing, 2002. Smart mobs: the next social revolution. Cambridge:

TARDE, Gabriel. A opinião e as massas. São Paulo: Martins Fontes, 1992. . Monadologia e sociologia. Petrópolis: Vozes, 2003. 